\title{
APLICACIÓN DEL FLIPPED LEARNING Y REALIZACIÓN DE UN \\ CUADERNO DE LABORATORIO EN PRÁCTICAS DE TÉCNICAS INSTRUMENTALES DE BIOLOGÍA CELULAR
}

Application of flipped learning and development of a laboratory notebook for the practical sessions in Techniques of Cellular Biology

Aplicação de flipped learning e desenvolvimento de um caderno de laboratório para as sessões práticas em Técnicas de Biologia Celular

\section{Felipe Martínez Pastor}

Departamento de Biología Molecular (Biología Celular), Universidad de León, España. Teléfono: +34 987291000+5679. Correo electrónico: felipe.martinez@unileon.es

\section{Resumen}

En esta comunicación se describe una experiencia llevada a cabo durante los cursos 12/13 a 16/17, aplicando dos actividades para mejorar el aprendizaje en las prácticas de la asignatura Técnicas Instrumentales I (Biología Celular) de $1^{\circ}$ del Grado de Biotecnología. Nos basamos en flipped learning (proporcionando material y proponiendo test previos) para motivar a los alumnos a revisar los contenidos antes de las clases, y se realizó un cuaderno de laboratorio en vez de uno de prácticas. El análisis de las calificaciones y de una encuesta posterior mostró que los alumnos consideraron favorablemente las actividades y su impacto en el aprovechamiento de las prácticas. Concluimos que las metodologías flipped learning pueden mejorar el aprendizaje al motivar la revisión del material docente, y que la actividad "cuaderno de laboratorio" puede ser interesante y profesionalizante, aunque hay que tener en cuenta la actitud de los alumnos para asumir este reto.

Palabras clave: flipped learning; cuaderno de laboratorio; Moodle; metodologias activas

\footnotetext{
Abstract

We describe an experience carried out from the 12/13 to $16 / 17$ courses, applying two activities for learning improvement in the practices of the subject Instrumental Techniques I (Cell Biology), $1^{\text {st }}$ course of the Biotechnology degree. Flipped learning Aplicación del flipped learning y realización de un cuaderno de laboratorio en prácticas de técnicas instrumentales de biología celular 
was used to motivate students to review the contents prior to practice (providing material and testing), and using a laboratory notebook, rather than a conventional practices notebook. Grades analysis and a subsequent survey showed that the students considered both activities favorably, as well as their impact on the learning process in the practices. Flipped learning methodologies can contribute to the improvement of learning by motivating the revision of the teaching material, and the laboratory notebook activity can be very interesting and professionalizing, although it is necessary to take into account the attitude of the students to face such a challenge.

Keywords: flipped learning; lab notebook; Moodle; survey

\section{Resumo}

Uma experiência realizada durante o curso 12/13 a 16/17, utilizando duas atividades para melhorar a aprendizagem nas práticas das Técnicas Instrumentais I (Biologia Celular) 1st Grade Biotecnologia. Aprendizagem baseada em flipped learning (fornecimento de temas e propor testes anteriores) foi realizada para motivar os alunos para avaliar o material, e um caderno de laboratório foi realizado em vez de um caderno de práticas. A análise das notações e uma pesquisa mais tarde mostrou que os estudantes considerados favoravelmente ambas as atividades e seu impacto sobre a utilização de práticas. Conclui-se que as metodologias tipo de aprendizagem flipped learning pode contribuir para a melhoria da aprendizagem, incentivando a revisão de materiais de ensino, e que a atividade "caderno de laboratório" pode ser muito interessante e profissionalizante, mas deve levar em conta a atitude dos estudantes para assumir este desafio.

Palavras-chave: flipped learning; caderno de laboratório; Moodle; inquérito

\section{Introducción}

Un aprendizaje efectivo requiere de metodologías activas que consideren al estudiante como sujeto activo que construye su conocimiento. El docente debería utilizar metodologías que promuevan esa actitud activa, y el denominado flipped learning (clase al revés) resulta muy atractivo en numerosos contextos (Mendoza, 2015). Básicamente, el profesor pone a disposición el material docente, incluyendo a menudo grabaciones de 
las lecciones, para que los estudiantes utilicen ese material autónomamente. El tiempo presencial con el docente se puede emplear en otras actividades (resolución de dudas, problemas, etc.), mejorando el aprendizaje. En el caso de la docencia práctica, es de gran ayuda que los estudiantes adquieran previamente conocimientos sobre aquellas técnicas que van a aprender.

Otro aspecto interesante de las prácticas es que estén orientadas a la adquisición de competencias profesionalizantes. El uso correcto del cuaderno de laboratorio como herramienta de trabajo es una competencia muy demandada por las empresas biotecnológicas y los laboratorios. En $5^{\circ}$ curso de Licenciatura en Biotecnología (Martínez-Pastor, Robles, Fernández-López, 2012), sustituimos el clásico cuaderno de prácticas por la realización de un cuaderno de laboratorio, según las normas al uso. Esta actividad tuvo una buena aceptación, pero ignoramos el efecto en estudiantes de primeros cursos.

En esta comunicación se narra otra experiencia docente realizada durante cinco cursos consecutivos, en la que se combinaron técnicas propias del flipped learning con la preparación de un cuaderno de laboratorio en primer curso del Grado en Biotecnología.

\section{Contextualización}

La experiencia se realizó del curso $12 / 13$ al 16/17 en la asignatura Técnicas Instrumentales I de primer curso del Grado de Biotecnología de la Universidad de León (mediana de 52 alumnos). Esta es una asignatura obligatoria de 6 ECTS impartida entre tres Áreas (Bioquímica, Biología Celular y Microbiología). La experiencia se desarrolló en la parte práctica de Biología Celular (3 grupos, 5 prácticas de 2 h). Cabe destacar que el acceso al Grado de Biotecnología es altamente vocacional, con elevada nota de corte y buena actitud de los alumnos.

\section{Diseño y desarrollo}

Desde el principio del curso, se puso a disposición de los estudiantes (aula virtual Moodle) todo el material necesario: guiones, documentos específicos y vídeos explicativos. Se les informó de que unos días antes de cada práctica podrían realizar un test para comprobar la adquisición de conocimientos. Contestar correctamente al menos 7 preguntas de 10 sumaba 0,2 puntos a la evaluación.

Aplicación del flipped learning y realización de un cuaderno de laboratorio en prácticas de técnicas instrumentales de biología celular 
En cuanto al cuaderno de laboratorio, se les proporcionó la información sobre la forma de realizarlo, insistiendo en que no era un cuaderno “de prácticas”. De hecho, el cuaderno debía permanecer en el laboratorio, sin posibilidad de hacer enmiendas. Tras las prácticas, el docente evaluó los cuadernos de acuerdo con la rúbrica mostrada en la Tabla 1 (total de 2 puntos en la calificación general).

Tabla 1.

Rúbrica utilizada para calificar los cuadernos de laboratorio

\begin{tabular}{|c|c|c|c|}
\hline & Buena [8-10] & Regular [5-8) & Mala [0-5) \\
\hline Estructura (40\%) & $\begin{array}{l}\text { Cumple las normas } \\
\text { (numeración, índice, } \\
\text { tachaduras, espacios libres } \\
\text { anulados, firmas, fechas, } \\
\text { etc.) }\end{array}$ & $\begin{array}{l}\text { Fallos en alguna norma: } \\
\text { faltan fechas o } \\
\text { numeración, uso de } \\
\text { líquido corrector, sin } \\
\text { firmas, etc. }\end{array}$ & $\begin{array}{l}\text { Incumple muchas } \\
\text { normas de estructura. }\end{array}$ \\
\hline Contenido (30\%) & $\begin{array}{l}\text { Se indica el objetivo de la } \\
\text { práctica, un esquema de los } \\
\text { pasos experimentales, se } \\
\text { indican factores importantes } \\
\text { como temperaturas, } \\
\text { indicaciones de seguridad, } \\
\text { etc. }\end{array}$ & $\begin{array}{l}\text { No se hace una breve } \\
\text { introducción con los } \\
\text { objetivos, faltan } \\
\text { indicaciones de } \\
\text { seguridad o elementos } \\
\text { importantes. Cálculos o } \\
\text { fórmulas incorrectas, } \\
\text { etc. }\end{array}$ & $\begin{array}{l}\text { No se indican objetivos, } \\
\text { faltan pasos } \\
\text { importantes, no hay } \\
\text { advertencias de } \\
\text { seguridad. }\end{array}$ \\
\hline Presentación (30\%) & $\begin{array}{l}\text { Se explica de forma clara y } \\
\text { concisa lo que se ha hecho. } \\
\text { Se especifican los cálculos, } \\
\text { se incluyen imágenes si son } \\
\text { precisas, expresión correcta } \\
\text { (ortografía, terminología, } \\
\text { etc.). }\end{array}$ & $\begin{array}{l}\text { Expresión confusa, } \\
\text { errores ortográficos o } \\
\text { gramaticales, dibujos } \\
\text { incorrectos o que no } \\
\text { son necesarios. }\end{array}$ & $\begin{array}{l}\text { Se explica la } \\
\text { realización de la } \\
\text { práctica o sus } \\
\text { resultados de forma } \\
\text { incorrecta, muy confusa } \\
\text { o recargada. Muchos } \\
\text { errores ortográficos o } \\
\text { gramaticales. }\end{array}$ \\
\hline
\end{tabular}

\section{Evaluación}

La evaluación de la experiencia se llevó a cabo utilizando información tanto de las calificaciones como de una encuesta anónima en el aula virtual tras la finalización del semestre (mediana de 19 participantes, aunque hubo 47 en el curso 2014-15). El 99\% de los estudiantes realizó los test previos a las prácticas, el 78\% puntuando en los 5 y el 94\% al menos en 4 . En la encuesta, un 52\% indicó que los tests les indujeron a revisar el material, y para los restantes fue un estímulo (un 21\% no habría revisado el material en otro caso, y sólo un 17\% lo habría hecho de todas maneras). De hecho, a un 91\% hacer los test le ayudó a realizar las prácticas (de manera muy relevante para el 48\%). Aunque algunos comentarios (texto libre) indicaban que habían tenido que realizar un esfuerzo extra, el 49\% destacó la mejor calidad del aprendizaje.

Aplicación del flipped learning y realización de un cuaderno de laboratorio en prácticas de técnicas instrumentales de biología celular 
En cuanto al cuaderno de laboratorio, el 84\% opinó que había sido más interesante que el clásico cuaderno de prácticas. De hecho, aunque suponía una actividad novedosa y un reto, la mediana de las calificaciones del cuaderno fue de 8,7 (intercuartil 8-9,3).

Globalmente, casi todos opinaron que las prácticas fueron útiles (84\%), con variaciones muy ligeras entre cursos en calificaciones y encuesta.

\section{Conclusiones}

Las metodologías basadas en el flipped learning son efectivas para motivar a los estudiantes en la revisión del material docente previamente a las prácticas, lo cual puede mejorar el proceso de aprendizaje. La inclusión de actividades de realización de un cuaderno de laboratorio ha resultado asequible y bien valorada por estudiantes de primer curso de Biotecnología. Hay que considerar que son estudiantes con buen nivel previo, antes de extrapolar estos resultados a otros grados.

\section{Referencias}

Martínez Pastor, F., Robles, V., \& Fernández-López, A. (2012). Evaluación por parte de estudiantes de Biotecnología de la actividad docente dirigida a adquirir la competencia "uso del cuaderno de laboratorio". En Actas de las VI Jornadas de docencia de la Sociedad Española de Biología Celular (pp. 15-16).

Mendoza, V. I. (2015). Flipped Classroom y la adquisición de competencias en la enseñanza universitaria online. Opción, 31(1). Recuperado a partir de http://produccioncientificaluz.org/index.php/opcion/article/view/20664 